\title{
Synthesis and Electrochemical Performance of Polyacrylonitrile Carbon Nanostructure Microspheres for Supercapacitor Application
}

\author{
Mimgjie Ma, ${ }^{1}$ Chao Zhang, ${ }^{1}$ Guangxu Huang, ${ }^{1}$ Baolin Xing, ${ }^{1}$ Yuling Duan, ${ }^{2}$ \\ Xiaojiao Wang, ${ }^{3}$ Zhengpeng Yang, ${ }^{1}$ and Chuanxiang Zhang ${ }^{1}$ \\ ${ }^{1}$ School of Materials Science and Engineering, Henan Polytechnic University, Jiaozuo 454000, China \\ ${ }^{2}$ School of Energy Science and Engineering, Henan Polytechnic University, Jiaozuo 454000, China \\ ${ }^{3}$ Dongpeng Ceramics Co., Ltd., Foshan 528031, China \\ Correspondence should be addressed to Chuanxiang Zhang; zcx223@hpu.edu.cn
}

Received 10 May 2015; Revised 10 July 2015; Accepted 26 July 2015

Academic Editor: Peter Reiss

Copyright (C) 2015 Mimgjie Ma et al. This is an open access article distributed under the Creative Commons Attribution License, which permits unrestricted use, distribution, and reproduction in any medium, provided the original work is properly cited.

Polyacrylonitrile (PAN) carbon nanostructure microspheres (CNM) with the average particle size of $200 \mathrm{~nm}$ were prepared in the range of 500 to $800^{\circ} \mathrm{C}$. The precursors of $\mathrm{CNM}$ were obtained through soap-free emulsion polymerization followed by freeze drying, oxidative stabilization, and half-carbonization. $\mathrm{KOH}$ was employed as the activation agent of the precursor material, and the ratio between $\mathrm{KOH}$ and the precursor was selected as $2: 1$. The element content, pore structure, nitrogen-containing functional groups, and microstructure characterization were characterized via elemental analysis, $\mathrm{N}_{2}$ adsorption at low temperature, $\mathrm{X}$-ray photoelectron spectroscopy (XPS), scanning electron microscopy (SEM), and transmission electron microscopy (TEM), and the electrochemical properties were examined as well. The results revealed that the CNM displayed specific surface area as high as $2134 \mathrm{~m}^{2} / \mathrm{g}$ and the total pore volume could reach $2.01 \mathrm{~cm}^{3} / \mathrm{g}$ when the activation temperature was $700^{\circ} \mathrm{C}$. Furthermore, its specific capacitance in $3 \mathrm{M} \mathrm{KOH}$ and $1 \mathrm{M}$ organic electrolyte could reach $311 \mathrm{~F} / \mathrm{g}$ and $179 \mathrm{~F} / \mathrm{g}$, respectively. And, also, abundant functional groups of N-5 and N-6 were rich in the surface of the material, which could cause Faraday reaction and got the increasing specific capacitance via improvement of the wettability of the electrode material.

\section{Introduction}

Supercapacitors have attracted great interest in energy storage due to their large power capability, high efficiency, and long cycle life [1]. A supercapacitor setup consists of current collector, electrode, electrolyte, and diaphragm. Among them, materials of electrode act as the critical components. A wide range of porous carbons, such as activated carbon, carbidederived carbon, carbon onions, carbon nanotubes, carbon aerogel, templated carbon, and carbon nanofibers, have been synthesized [2]. Among them, active carbon (AC) is widely used. However, AC may possess different structures and electrochemical characteristics due to the difference of the precursor and the production process.

Pietrzak et al. [3] reported that unique physical and chemical properties of carbon materials depended on not only developed specific surface area but the type, quantity, and way of bonding of heteroatom which exists on the surface of materials. And nitrogen was mentioned to be an important element to modify the property of the material surface. Strelko et al. [4] highlighted the concept of band gap $(\Delta E)$, indicating that electronic transmission would be easier if the band gaps of functional groups were diminished. It has been obtained by calculation of quantum chemistry: $\Delta E$ of $\mathrm{N}-\mathrm{X}$ is the maximum, N-Q follows, and N-6 is calculated to be the minimum. Seredych et al. [5] identified that N-6 and N-5 (the nitrogen atoms which are on the verge of graphite ring) were the optimum functional groups to give rise to Faraday reaction.

Compared with the traditional active carbon which is based on wood and mineral, polyacrylonitrile (PAN) contains a higher content of nitrogen, whose theoretical 
content of nitrogen is approximate to $26.42 \%$. The subsequent processes such as carbonization can engender abundant surface functional groups of nitrogen, which can improve the surface physical and chemical properties of electrode materials. Moreover, PAN microspheres obtained via soapfree emulsion polymerization avoid many adverse effects on electronic, optical, and surface properties in comparison to the product of other polymerizations [6]. Different from other polymer derived carbons $[7,8]$, PAN contains only two elements of carbon and nitrogen, both of which are inert elements, so it is relatively safe and more convenient to operate. Moreover, the effect of other elements on carbide can be also excluded. Electrode materials can be fabricated by subjecting nitrogen-containing materials of an appropriate polymer precursor to stabilization and carbonization processes. So far AC produced from PAN has been subjected to different physical or chemical activation processes using steam, $\mathrm{CO}_{2}$, or $\mathrm{NaOH}$ to create pores. The activation process further increases the specific surface area of carbon nanofibers thereby enhancing the specific capacitance. Moreover, the activation step can modify the surface functionalities of AC, causing the cycling instability of supercapacitors.

The function of nitrogen has been widely reported in recent literatures. Zhao et al. [9] utilized milk powder as the precursor and prepared $\mathrm{N}$-doped multilayer grapheme (N-MLG) under the presence of $\mathrm{Fe}^{2+}$ ions as catalyst. The product was measured on electrochemical performance and the result showed that the onset potential $(-0.05 \mathrm{~V})$ of the N-MLG 45 min sample was significantly higher than that of the CNTs $(-0.25 \mathrm{~V})$ and undoped graphene $(-0.24 \mathrm{~V})$, which indicates that $\mathrm{N}$ plays an important role in electrochemical performance.

In this work, we provide a facile route to fabrication of porous carbon from acrylonitrile monomer by using $\mathrm{KOH}$ as activation agent under different temperature. The pore structure, electrochemical performance, and effects of nitrogen-containing functional groups on the electrochemical properties have been investigated.

\section{Experimental}

2.1. Preparation and Oxidative Stabilization of PAN Microspheres. $300 \mathrm{~mL}$ deionized water and $30 \mathrm{~mL}$ acrylonitrile (purchased from Tianjin Comio chemical reagents development center) were firstly poured into four-necked flask under gentle stirring. Subsequently, the samples were heated to $60^{\circ} \mathrm{C}$ at a rate of $2^{\circ} \mathrm{C} / \mathrm{min}$, and then $30 \mathrm{mg}$ potassium persulfate (purchased from Tianjin FengChuan Chemical Reagent Technology Co., Ltd., and dissolved in deionized water) was injected to trigger the reaction and held for 6 hours. The whole reaction was proceeded in nitrogen atmosphere. Finally, stabilization was managed by thermal treatment under nitrogen gas $(100 \mathrm{~mL} / \mathrm{min})$ by raising the temperature at a rate of $1^{\circ} \mathrm{C} / \mathrm{min}$ to $300^{\circ} \mathrm{C}$. After being cooled naturally to room temperature, the precursor was prepared.

2.2. Carbonization and Activation Process for Fabrication of $A C$. The ratio between $\mathrm{KOH}$ and the precursor was optimized, and the alkaline-precursor mass ratio of 2 was employed in the experiment. A moderate amount of deionized water was added to the mixture under gentle stirring and poured into a nickel crucible after impregnation for $24 \mathrm{~h}$. The samples were heated to the activation temperature at a rate of $10^{\circ} \mathrm{C} / \mathrm{min}$ under nitrogen gas flow $(50 \mathrm{~mL} / \mathrm{min})$ and kept for $1 \mathrm{~h}$. To remove the residual potassium atoms or ions, the produced sample was immersed in $5 \mathrm{M} \mathrm{HCl}$ solution for 24 hours and then rinsed with deionized water until the $\mathrm{PH}$ was 7 and dried at $120^{\circ} \mathrm{C}$ for $5-8 \mathrm{~h}$. The resultant products were named as $x \mathrm{AQ} y$ ( $x$ and $y$ represent mass ratio of alkalineprecursor and activation temperature, resp.).

2.3. Characterization and Analysis. Specific surface area and pore structure were measured at $77 \mathrm{~K}$ on $\mathrm{N}_{2}$ adsorption (Quantachrome, US; model: Autosorb-iQ-MP). The surface functional groups of the prepared samples were determined through X-ray photoelectron spectroscopy (XPS, PHI, US; model: PHI 5000C ESCA System X). The content and occurrence forms of nitrogen were determined by Elemental Analyzer (Elementar, Germany; model: Vario Macro Cube). The external morphology of the CNM was explored using scanning electron microscopy (SEM, JEOL, Japan; model: JSM-6390LV) and transmission electron microscopy (TEM, JEOL, Japan; model: JEM2100). The contact angle $(\theta)$ was determined using contact angle measurement instrument (model: JC2000C1) to characterize the wettability of electrode materials.

\subsection{Preparation of Electrodes and Assembly of Supercapacitor.} The working electrodes were fabricated by mixing $85 \mathrm{wt} \%$ PAN CNM powders with $10 \mathrm{wt} \%$ acetylene black and $5 \mathrm{wt} \%$ polytetrafluoroethylene (PTFE) binder. A small amount of ethanol was added to the mixture to produce a homogeneous paste. Then the electrodes were dried under vacuum at $120^{\circ} \mathrm{C}$ for $4 \mathrm{~h}$. The supercapacitors were assembled with two electrodes using $3 \mathrm{M} \mathrm{KOH}$ and $1 \mathrm{M} \mathrm{Et}_{4} \mathrm{NBF}_{4} / \mathrm{PC}$ solution as the electrolyte, respectively.

2.5. Characterization of Electrochemical Properties. The galvanostatic charge/discharge and cyclic voltammetry test were carried out on an Arbin Instrument. Electrochemical impedance spectroscopy was recorded on PARSTAT2273 Advance Electrochemical System and each data point in Nyquist plot is at a different frequency from $100 \mathrm{KHz}$ to $0.001 \mathrm{~Hz}$. The specific capacitance of a single CNM electrode was calculated from the discharge part of galvanostatic charge/discharge curves by the following formula:

$$
C=\frac{2(I \times \Delta t)}{m \times \Delta V}
$$

where $I$ was the discharge current (A), $\Delta t$ was the discharge time (s), $\Delta V$ was the variation of potential $(V)$ in discharge process, and $m$ was the mass (g) of AC in one electrode. 
TABLE 1: Element content of samples at different activation temperature.

\begin{tabular}{lcccc}
\hline Sample ID & $\mathrm{N}(\%)$ & $\mathrm{C}(\%)$ & $\mathrm{H}(\%)$ & $\mathrm{N} / \mathrm{C}(\%)$ \\
\hline 2AQ5 & 17.39 & 58.63 & 2.93 & 41.95 \\
2AQ6 & 13.1 & 61.08 & 3.85 & 21.45 \\
2AQ7 & 7.58 & 75.90 & 1.81 & 14.12 \\
2AQ8 & 2.34 & 86.56 & 0.95 & 3.77
\end{tabular}

\section{Results and Discussion}

3.1. Microstructure Characterization of PAN Microspheres. The external pore structure of PAN microspheres and its activated forms are observed by SEM and TEM. As shown in Figure 1, (b) and (d) display the images of PAN microspheres which are obtained by the method of soap-free emulsion polymerization. We can realize that, whether before or after the carbonization, the precursors and produced carbon nanostructure microspheres can maintain an inerratic spherical shape, and the average particle size of the sphere stays around $200 \mathrm{~nm}$. The morphology of 2AQ8 and PAN microspheres was further characterized by TEM. As seen in Figures 1(c), 1(d), 1(e), and 1(f), these spheres showed abundant porosity with nanostructure, and the average particle size was about $200 \mathrm{~nm}$, which was in good agreement with SEM observation.

3.2. Element Content of CNM Based on PAN. Table 1 shows the element content of samples at different activation temperature. The nitrogen content decreases gradually with the increase of temperature; the content of carbon increases due to the augment of the degree of carbonization, leading to the decrease of N/C. On one hand, PAN had met with structural changes such as cyclization [10] after oxidation and carbonization, which might produce acrylamide, $\mathrm{HCN}, \mathrm{NH}_{3}$, $\mathrm{CO}_{2}$, and acetamide [11,12] and bring about the decrease of nitrogen content. On the other hand, the etching effect of $\mathrm{KOH}$ might promote the structural changes in the activation process.

\subsection{The Specific Surface Area and Pore Structure of CNM Based} on PAN. As shown in Figure 2, 2AQ5 and 2AQ6 exhibit a terrible property of adsorption demonstrated on the ordinate, which is corresponding to a small adsorption platform. It was observed that the adsorption platform of the samples under 700 and $800^{\circ} \mathrm{C}(2 \mathrm{AQ} 7 / 2 \mathrm{AQ} 8)$ was improved significantly and a certain hysteresis loop appeared, which indicates that both of the samples possess high specific surface area and a certain mesopore structure.

The BET surface area, pore size distribution, and mesopores rate were listed in Table 2. The specific surface area increased from 17 to $3065 \mathrm{~m}^{2} \cdot \mathrm{g}^{-1}$ with the increase of activation temperature from 500 to $800^{\circ} \mathrm{C}$. This is in good agreement with the adsorption-desorption isotherms in Figure 2.

$\mathrm{KOH}$ can be transformed into $\mathrm{K}_{2} \mathrm{O}$ after dehydration by time and it played as the activation agent for porous carbon materials. The development of pore structure depends primarily on the formation of $\mathrm{K}_{2} \mathrm{CO}_{3}$ derived from the
TABLE 2: Porosity parameters of the PAN carbon materials.

\begin{tabular}{lccccc}
\hline Sample ID & $\begin{array}{c}S_{\mathrm{BET}} \\
\left(\mathrm{m}^{2} \cdot \mathrm{g}^{-1}\right)\end{array}$ & $\begin{array}{c}V_{t} \\
\left(\mathrm{~cm}^{3} \cdot \mathrm{g}^{-1}\right)\end{array}$ & $\begin{array}{c}V_{\text {mic }} \\
\left(\mathrm{cm}^{3} \cdot \mathrm{g}^{-1}\right)\end{array}$ & $\begin{array}{c}V_{\text {mec }} \\
\left(\mathrm{cm}^{3} \cdot \mathrm{g}^{-1}\right)\end{array}$ & $\begin{array}{c}V_{\text {mec }} / V_{t} \\
(\%)\end{array}$ \\
\hline 2AQ5 & 17 & 0.05 & 0.032 & 0.052 & 36.00 \\
2AQ6 & 662 & 0.42 & 0.301 & 0.119 & 28.33 \\
2AQ7 & 2134 & 1.41 & 0.820 & 0.590 & 41.84 \\
2AQ8 & 3065 & 2.01 & 0.779 & 1.231 & 61.24 \\
\hline
\end{tabular}

TABLE 3: Species and content of $\mathrm{C}$ and $\mathrm{N}$ functional group on activation sample 2AQ7.

\begin{tabular}{lcc}
\hline N peak & $\begin{array}{c}\text { The electron binding } \\
\text { energy }(\mathrm{eV})\end{array}$ & $\begin{array}{c}\text { Functional group } \\
\text { content }(\%)\end{array}$ \\
\hline $\mathrm{N}-6$ & $398.8 \pm 02 \mathrm{eV}$ & 41.40 \\
$\mathrm{~N}-5$ & $400.4 \pm 02 \mathrm{eV}$ & 30.91 \\
$\mathrm{~N}-\mathrm{Q}$ & $401.4 \pm 02 \mathrm{eV}$ & 18.12 \\
$\mathrm{~N}-\mathrm{X}$ & $402.4 \pm 02 \mathrm{eV}$ & 9.54 \\
\hline
\end{tabular}

reaction between $\mathrm{K}_{2} \mathrm{O}$ and carbon, and the reduction of metallic potassium from $\mathrm{K}_{2} \mathrm{O}$ plays a positive role under high temperature as well. The former consumes carbon atoms of precursor to generate pores and the latter completes the process by the strong permeability and intercalation of potassium $[13,14]$. Because the boiling point of $\mathrm{K}$ is $762^{\circ} \mathrm{C}$, it is not conducive to the development of pores if the temperature is under $700^{\circ} \mathrm{C}$. In contrast, when the temperature is equal to or higher than the boiling point of K (as 2AQ8), the welldeveloped porosity and high specific surface area would be obtained.

The pore size distribution curve (Figure 3 ) indicated clearly that not only high porous volume within the scope of the microporous range $(<2 \mathrm{~nm})$ can be observed in 2AQ8; so does the scope of the mesoporous range $(2-5 \mathrm{~nm})$. The second is 2AQ7 and the porous volume of 2AQ5 and 2AQ6 is detected to be the worst. This is fully consistent with the results of the analysis in Table 2 and Figure 2.

3.4. Text of X-Ray Photoelectron Spectroscopy. The content and occurrence forms of nitrogen are shown in Table 3 and Figure 4. 2AQ7 contains abundant nitrogen-containing functional groups on the surface such as N-6, N-5, N-Q, and $\mathrm{N}-\mathrm{X}$. The proportion of $\mathrm{N}-6$ and $\mathrm{N}-5$, which are on the edge of graphite layer, has been detected to be the maximum. However, N-Q, derived from the substitute to carbon atoms in graphite layer, appears only with a small fraction.

\subsection{Electrochemical Performance}

3.5.1. Galvanostatic Charge/Discharge. Figure 5 shows the galvanostatic charge/discharge curves of PAN carbon materials under the current density of $50 \mathrm{~mA} / \mathrm{g}$ in both $\mathrm{KOH}$ and organic electrolyte. Combining the parameters with Table 4, the increase of the specific surface area contributes to the amplification of charge/discharge time and the specific capacitance in both inorganic and organic system, mostly. 


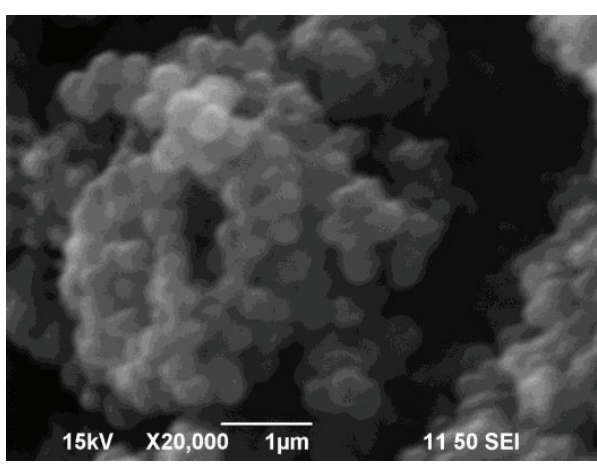

(a)

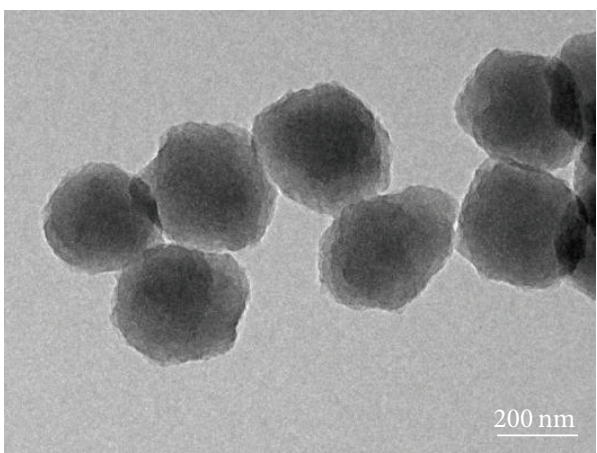

(c)

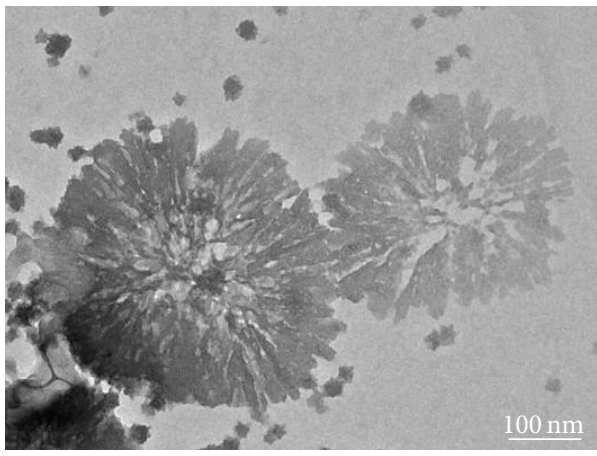

(e)

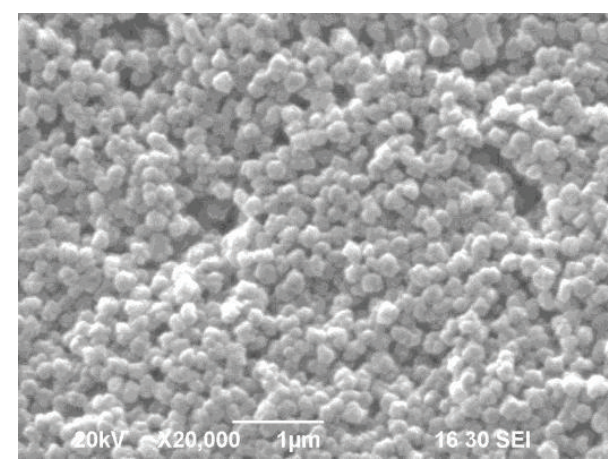

(b)

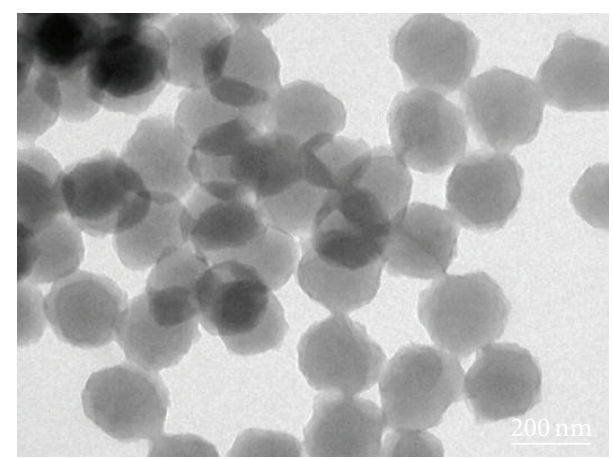

(d)

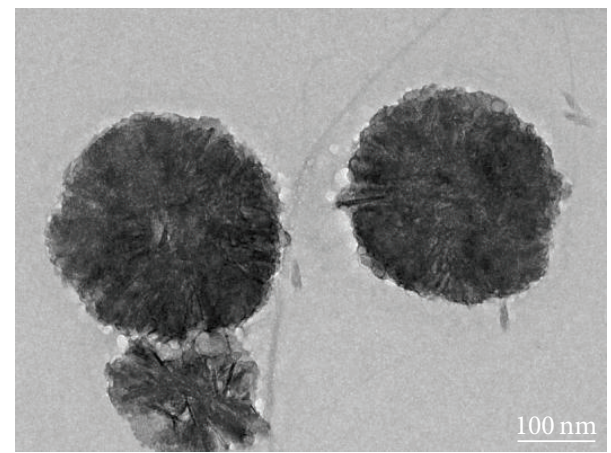

(f)

FIGURE 1: (a) The image of SEM of 2AQ8; (b) and (d) the images of SEM and TEM of PAN microspheres; (c), (e), and (f) the image of TEM of 2AQ8.

TABLE 4: Experimental and calculated specific capacitance of PAN carbon materials.

\begin{tabular}{|c|c|c|c|}
\hline \multirow[b]{2}{*}{ Sample ID } & \multirow[b]{2}{*}{$S_{\mathrm{BET}}\left(\mathrm{m}^{2} \cdot \mathrm{g}^{-1}\right)$} & \multicolumn{2}{|c|}{ Specific capacitance (F/g) } \\
\hline & & $\begin{array}{l}\text { Aqueous } \\
\text { electrolyte }\end{array}$ & $\begin{array}{l}\text { Organic } \\
\text { electrolyte }\end{array}$ \\
\hline 2AQ5 & 17 & 87 & 15 \\
\hline 2AQ6 & 662 & 208 & 56 \\
\hline 2AQ7 & 2134 & 311 & 179 \\
\hline 2AQ8 & 3065 & 236 & 175 \\
\hline
\end{tabular}

Curves of 2AQ5-2AQ7 exhibit different degrees of distortion in the range of $0-0.6 \mathrm{~V}$ in aqueous electrolyte while the 2AQ8 approaches ideal line (as shown in Figure 5(a)), suggesting that 2AQ8 reflects the characteristics of electric double layer capacitance (EDLC). On the one hand, the subordinate effect of pore structure (such as low mesoporous rate and small specific surface area) gives rise to a larger diffusion impedance of electrolyte ions into pores. On the other hand, the pseudocapacitance cripples the dominant position of EDLC and influences the charge/discharge property due to the existence of the redox reaction. 2AQ7 (Figure 5(b)) exhibits no linear bending in organic system in comparison with aqueous system and the reason is that high specific surface area and outstanding mesoporous rate render the pore subordinate. The redox reaction of nitrogen-containing functional groups (N-6 and N-5) on 2AQ7 produces pseudocapacitance and contributes to the specific capacitance in aqueous system. But the functional groups provide hardly 


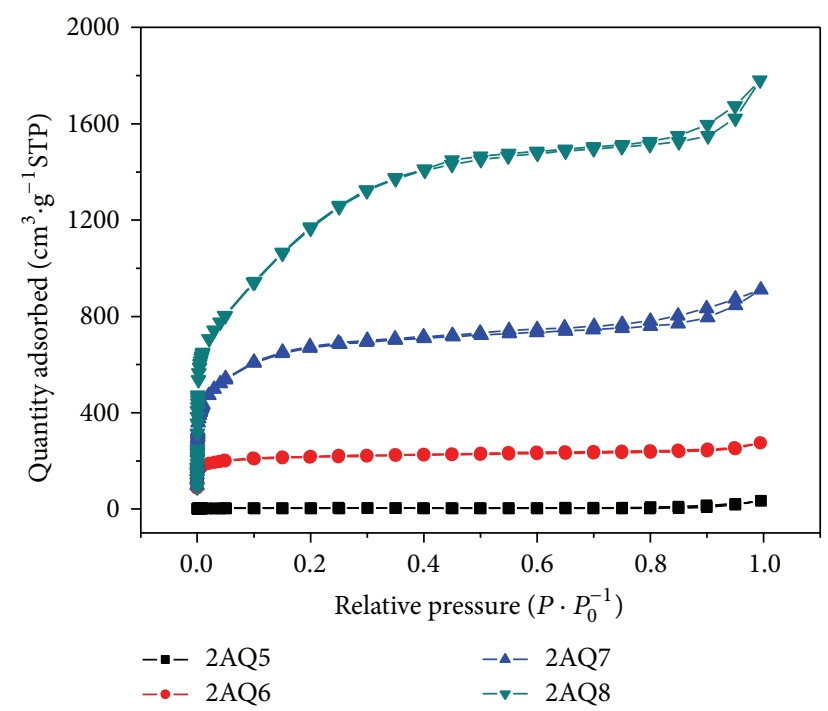

FIGURE 2: $\mathrm{N}_{2}$ adsorption-desorption isotherms of PAN carbon materials prepared at different activation temperature.

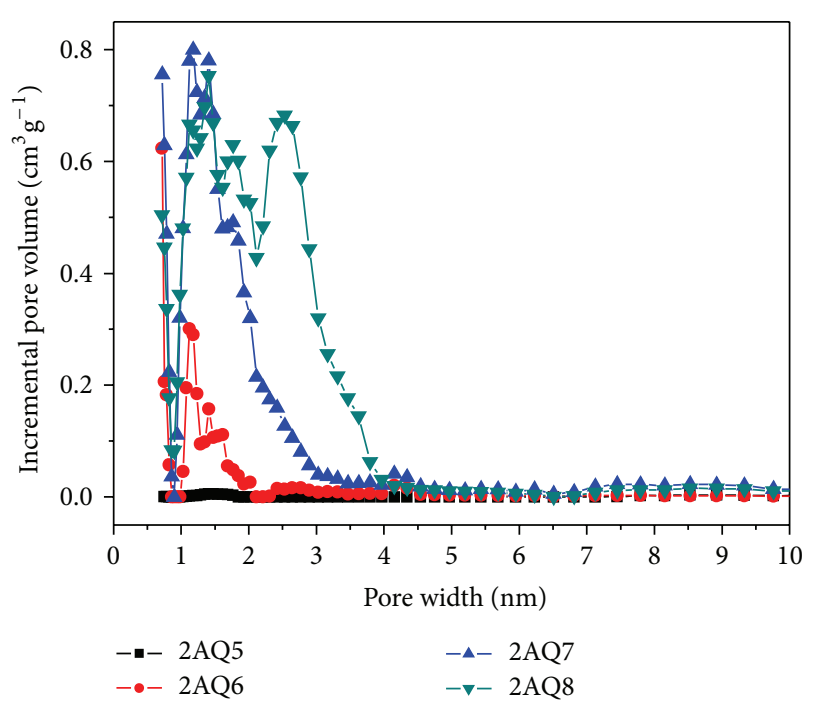

FIgURE 3: Pore size distributions of PAN carbon materials prepared at different activation temperature.

any Faraday reaction in organic system; thus it keeps the charge/discharge curves as the type of EDLC.

Figures 6 and 7 exhibit typical galvanostatic charge/ discharge cycle curves under the current density of $50 \mathrm{~mA} / \mathrm{g}$ in aqueous and organic electrolyte, respectively. In addition to the bending deformation in the first cycle in $\mathrm{KOH}$ electrolyte, the subsequent cycle curves of 2AQ7 act as basic isosceles triangles. The result demonstrates that (1) high specific surface area and abundant nitrogen-containing functional groups render the infiltration of electrolyte into the pores of 2AQ7 difficult and need an additional time and (2) oxidation reduction reaction on N-6 and N-5 delayed the electrolyte diffusion and consumed more transmission electrons, leading to the extension of charge/discharge time [15].

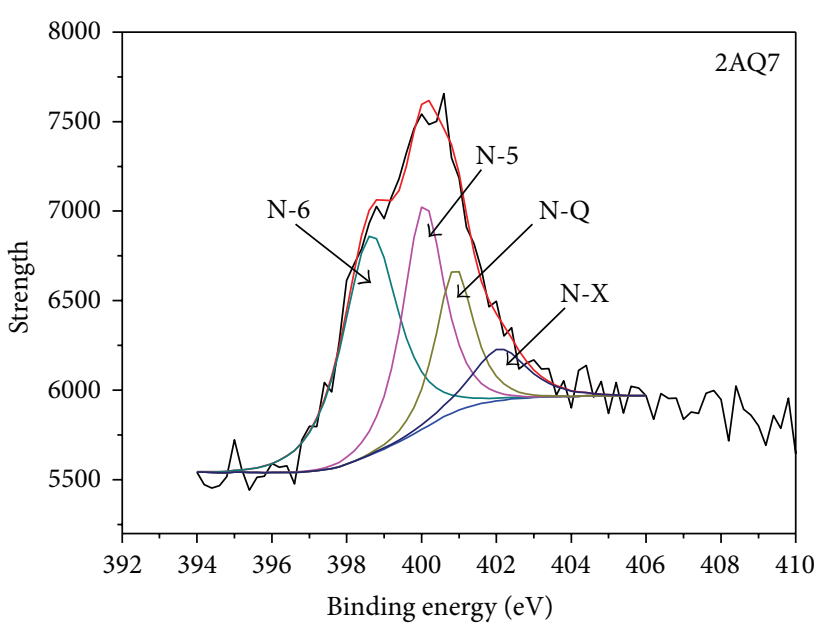

FIGURE 4: N peaks fitting curves of activation sample 2AQ7.

In $\mathrm{KOH}$ system, the charge/discharge efficiency keeps stable basically after the first five charge/discharge cycles; this indicates that pseudocapacitance reaction of N-6 and N-5 does not affect the charge/discharge performance but increases its specific capacitance. In organic system (Figure 7), the charge/discharge curves after the first cycle remain consistent, which indicates that N-6 and N-5 generate no adverse effects on organic electrolyte.

In order to further study the effect of surface functional groups on electrode materials, the wettability has been detected. As shown in Figure 8, the order of the size of contact angle $(\theta)$ can be determined as $2 \mathrm{AQ} 7>2 \mathrm{AQ} 5>$ 2AQ6 > 2AQ8. The specific surface area of 2AQ7 behaves inferiorly in comparison to $2 \mathrm{AQ} 8$, but it possesses the best surface wettability. This indicates that, by time the nitrogencontaining functional groups (N-6 and N-5) generate pseudocapacitance, improving the wettability and increasing the utilization of specific surface area and specific capacitance. Moreover, accompanying with the increase of activation temperature, the shrinkage of the quantity of nitrogen-containing functional groups makes for impairing the hydrophily. But its high mesoporous rate and specific surface area make up for the lack; specific capacitance in both kinds of electrolyte is still remarkable.

3.5.2. Cyclic Voltammetry. Cyclic voltammograms of electrode materials derived from CNM based on PAN in both aqueous electrolyte and organic electrolyte are displayed in Figure 9. Curves of 2AQ5 and 2AQ6 in two kinds of electrolytes are tortile significantly; it is mainly determined by the pore structure (small specific surface area and low pore rate). In aqueous system, serious distortion appeared in cyclic voltammetry curves of 2AQ7 in the voltage range of 0 $0.6 \mathrm{~V}$; this is in accordance with the charge/discharge curves (Figure 5(a)) in the same voltage range. Moreover, CV curves tend to swing outward in the voltage range of $0.2-0.7 \mathrm{~V}$, which indicate that redox reaction occurred on the surface groups in the charge/discharge process, improving the capacity of the capacitor [16]. In contrast, curve of 2AQ7 approximates to 


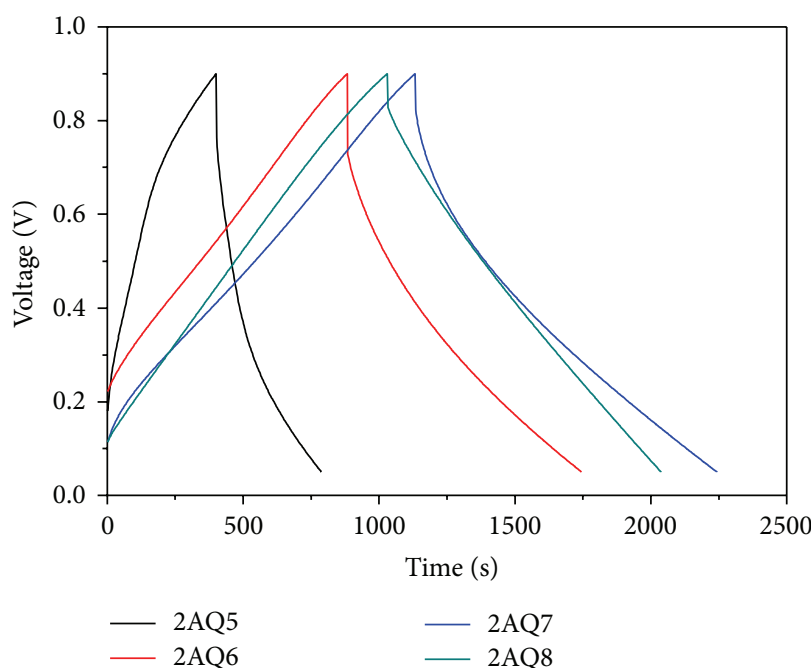

(a)

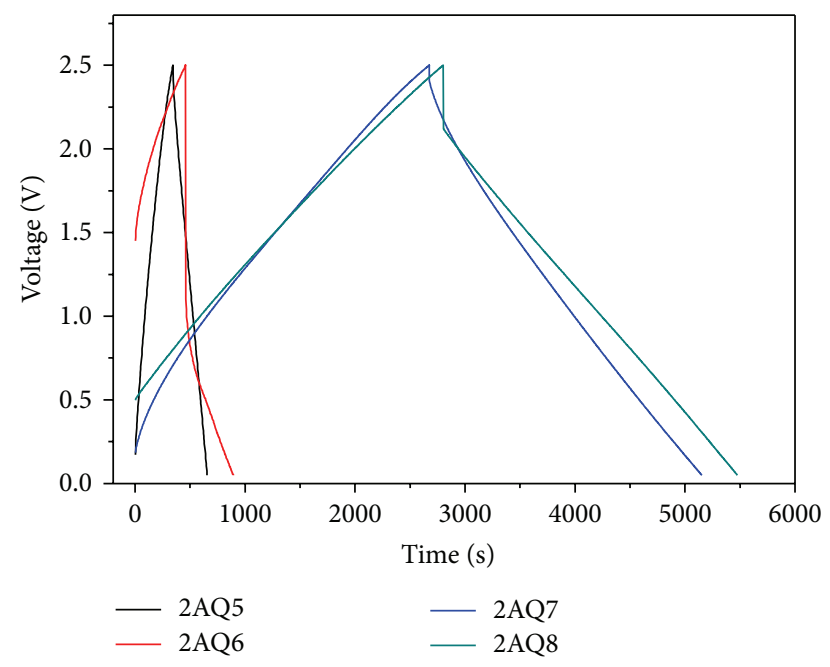

(b)

Figure 5: ((a) and (b)) Galvanostatic charge/discharge curves in $\mathrm{KOH}$ and $\left(\mathrm{C}_{2} \mathrm{H}_{5}\right)_{4} \mathrm{NBF}_{4} / \mathrm{PC}$ electrolyte of PAN carbon materials.

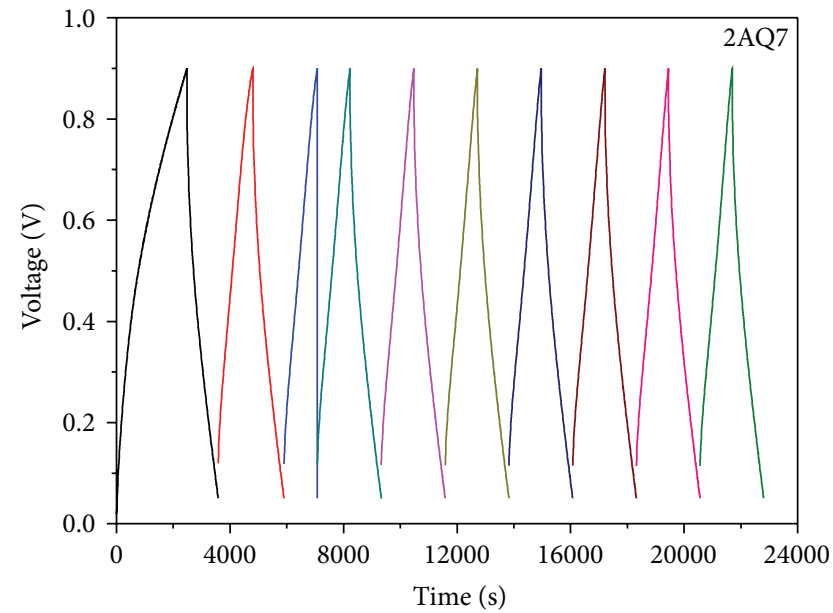

FIGURE 6: Galvanostatic charge/discharge cycle curves in $\mathrm{KOH}$ electrolyte of 2AQ7.

a rectangle and exhibits no distortion in organic system, which is in accordance with the charge/discharge curve in organic system (Figure 5(b)). It has fully demonstrated that the functional groups on the surface of 2AQ7 (N-6 and $\mathrm{N}-5$ ) produced pseudocapacitance in inorganic system and increased the specific capacitance. Small effect of pseudocapacitance on surface functional groups and high mesopores rate prompt the curve of 2AQ8 to exhibit a standard rectangular in both kinds of the system. The CV curves for 2AQ7 at different scan rate are shown in Figure 9(c). With increasing scan rate, the CV curves showed slight distortion, demonstrating a relatively good rate performance. The good electrochemical capacitive behavior of 2AQ7 may be attributed to its unique nanostructure shown in Figures 9(e) and 9(f).

The long-term cycle stability of the 2AQ7 was also examined by galvanostatic charge/discharge at a current

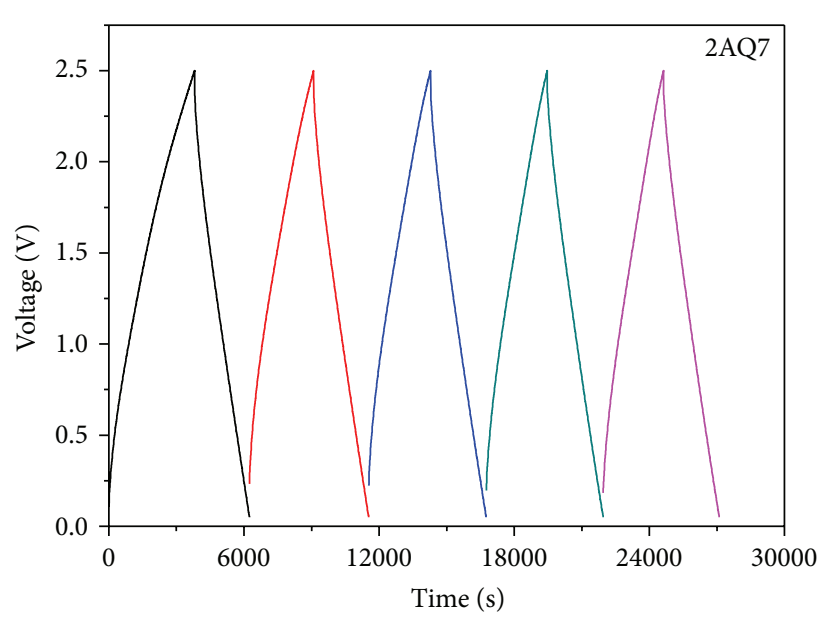

Figure 7: Galvanostatic charge/discharge cycle curves $\left(\mathrm{C}_{2} \mathrm{H}_{5}\right)_{4} \mathrm{NBF}_{4} / \mathrm{PC}$ electrolyte of 2AQ7.

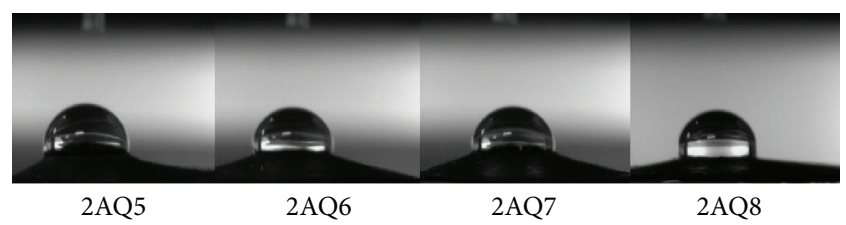

FIGURE 8: Contact angle of electrode materials prepared at different activation temperature.

density of $2.5 \mathrm{Ag}^{-1}$ for 100 cycles in $3 \mathrm{M} \mathrm{KOH}$ aqueous solution and the corresponding result is shown in Figure 9(d). There is $13 \%$ decrease of the initial specific capacitance after 100 cycles under such a strong current density. This is mainly because the redox reaction consumes parts of oxygen containing functional groups, leading to the decrease of specific capacitance with the increasing of cycle index. 


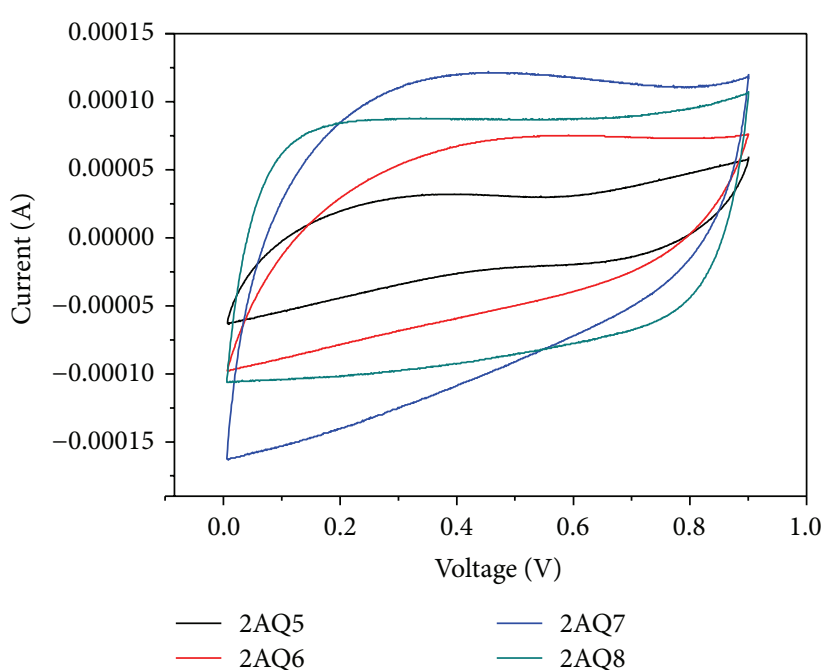

(a)

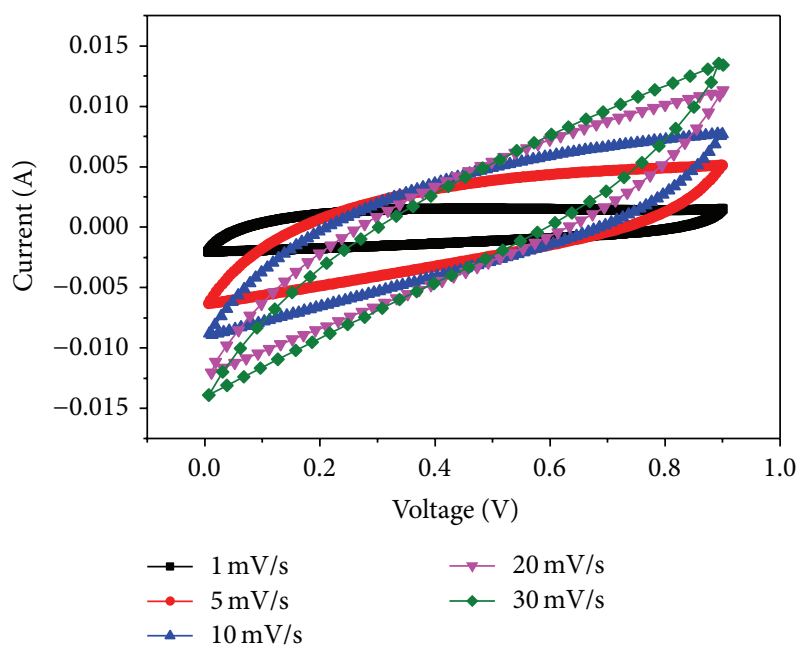

(c)

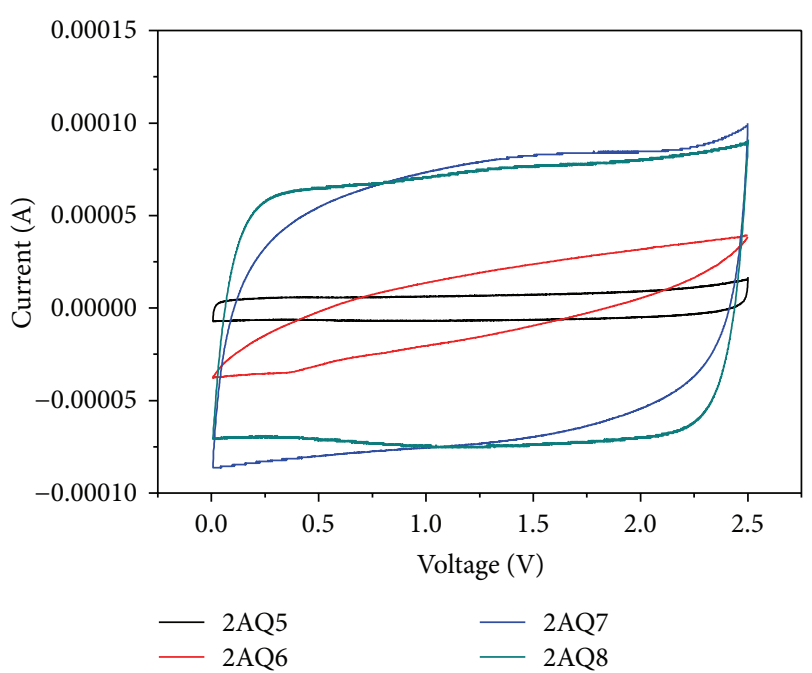

(b)

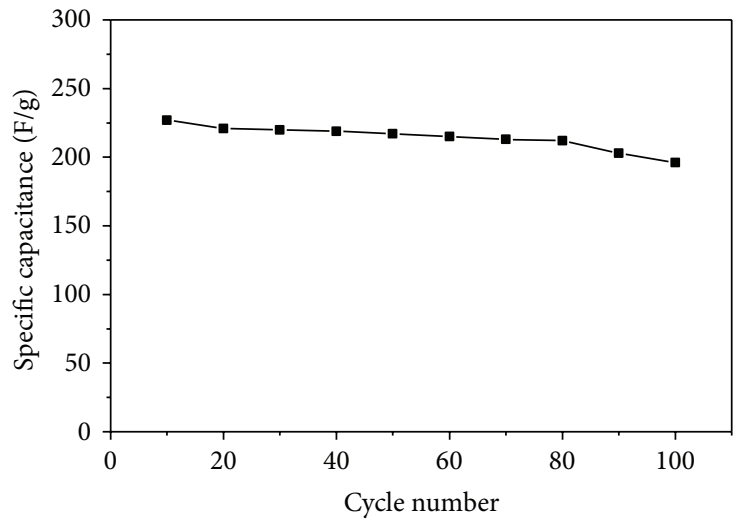

$\rightarrow-$ Specific capacitance

(d)

Figure 9: ((a) and (b)) CV curves in $3 \mathrm{M} \mathrm{KOH}$ and $\left(\mathrm{C}_{2} \mathrm{H}_{5}\right)_{4} \mathrm{NBF}_{4} / \mathrm{PC}$ electrolyte of PAN carbon materials (scan rate: $1 \mathrm{mV} / \mathrm{s}$ ), (c) CV curves of 2AQ7 electrodes at different scan rates in 1, 5, 10,20, and $30 \mathrm{mV} / \mathrm{s}$, and (d) cycle performance of 2AQ7 in $3 \mathrm{M} \mathrm{KOH}$ under a current density of $2.5 \mathrm{~A} / \mathrm{g}$.

For a further analysis of oxidation reduction reactions on nitrogen-containing functional groups, the reaction might occur in inorganic electrolyte as shown in Scheme $1[17,18]$.

3.5.3. AC Impedance. To analyse the performance of AC impedance, it is divided into three parts generally: lowfrequency, intermediate-frequency, and high-frequency region. The equivalent circuit is given in the inset of Figures $10(\mathrm{a})$ and 10(b). At very high frequencies, the intercept at real part $\left(Z^{\prime}\right)$ is an integrated resistance $\left(R_{e}\right)$ of ionic resistance of electrolyte and contact resistance at the active material/current collector interface. The slope of the $45^{\circ}$ portion of the curve is called the Warburg resistance $\left(R_{w}\right)$ and is a result of the frequency dependence of ion diffusion in the electrolyte to the electrode surface. High-frequency arc corresponds to the charge transfer resistance $\left(R_{\mathrm{ct}}\right)$ at the contact interface between electrode and electrolyte solution.
Because the curve of $2 \mathrm{AQ} 8$ is perpendicular to the real part $\left(Z^{\prime}\right)$ in low-frequency region (Figure 10(a)), it shows the best capacitance characteristics in both kinds of electrolyte and 2AQ7 follows. In contrast, the curves of 2AQ5 and 2AQ6 insist on declining and with no tend of verticality, which makes them the worst. All the evidences indicate that the capacitance of $2 \mathrm{AQ} 8$ is mainly supplied by EDLC. In contrast, curves of 2AQ5, 2AQ6, and 2AQ7 have deviated from the ideal in low-frequency region due to their pore structure and effect of pseudocapacitance.

In the intermediate-frequency region, the impedance of 2AQ5 and 2AQ6, which is presented as the slope of the $45^{\circ}$ portion of the curves, is relatively large. The reason is that the electrode contains a great deal of diffusion impedance because of the inferior pore structure, especially the small porosity of 2AQ5. The impedance of 2AQ7 in KOH electrolyte is significantly larger than that of organic system. Such result 


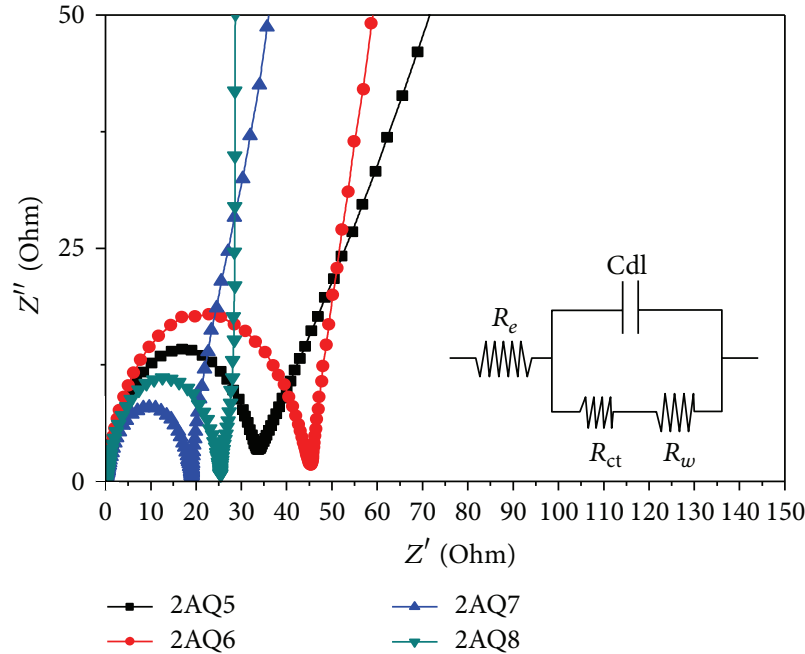

(a)

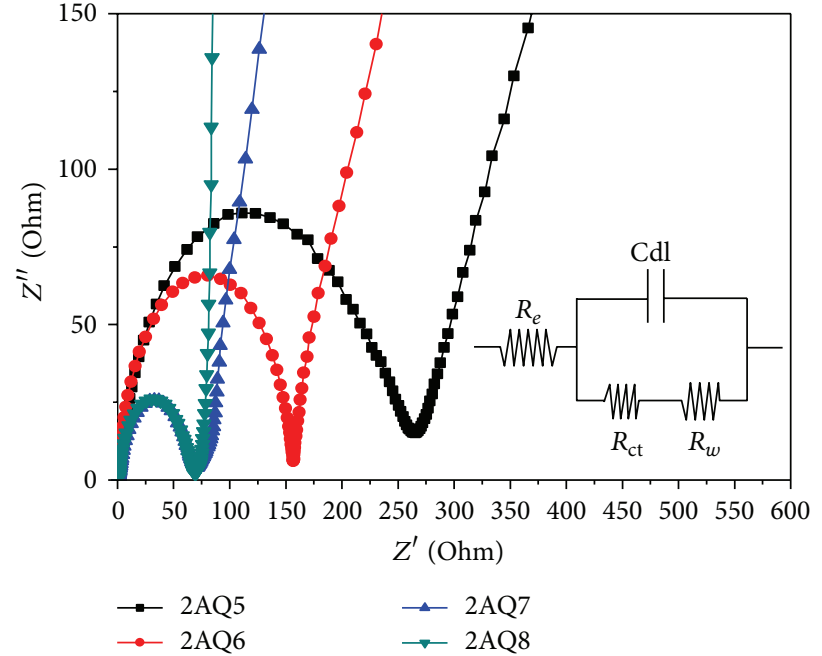

(b)

Figure 10: ((a) and (b)) AC impedance spectra in $\mathrm{KOH}$ and $\left(\mathrm{C}_{2} \mathrm{H}_{5}\right)_{4} \mathrm{NBF}_{4} / \mathrm{PC}$ electrolyte of PAN carbon materials.

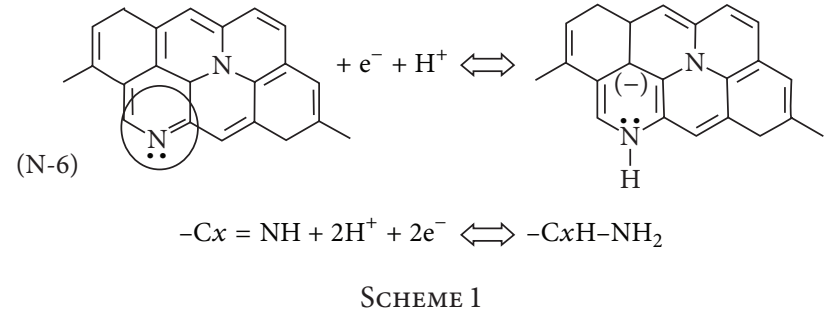

can be attributed to the fact that the pseudo capacitance reaction has occurred on nitrogen-containing functional groups of 2AQ7. Even though the nitrogen-containing functional groups increase the wettability of surface of electrode materials, they increase the diffusion impedance of electrolyte into the pores of electrode materials due to the redox reaction as well. For comparison, the high specific surface area and mesopores rate of $2 \mathrm{AQ} 8$ determine the diffusion impedance to be similar in both kinds of electrolyte system.

The size of arc diameter in high-frequency region reflects the size of internal impedance of the capacitor, which is concerned with the resistance between electrolyte and carbon materials, aperture, and particle of the materials. What is more, the contact impedance between carbon electrode and the collector is also included $[19,20]$. As shown in Figure 10, in the high-frequency region, the general trend of AC impedance spectra in both kinds of electrolyte system is semidiameter of the arc in inorganic system which is smaller than that of organic system, and the higher the temperature is, the smaller the semicircle diameter is. On the one hand, there are differences of properties between the two kinds of electrolyte itself. Resistivity of organic electrolyte is much higher than that of aqueous $(\mathrm{KOH})$ electrolyte, which makes the semicircle arc radius in high-frequency region of the two kinds of electrolyte different, essentially. On the other hand, accompanying with the increase of heat treatment temperature, the increase of conductivity and the decrease of resistance among particles contribute to the decrease of semicircular arc diameter.

3.5.4. Test of Leakage Current. Leakage current is an important index to measure the performance of supercapacitor [16]. Many causes can contribute to the appearance of leakage current. Briefly, it is mainly the result of joint action such as overcharge, reaction between surface functional groups of $\mathrm{AC}$ and electrolyte, and migration of ions on electric double layer to electrolyte [15]. Figure 11 exhibits the leakage current of the samples under different activation conditions. All of the leakage current is ignorable, revealing an outstanding stability.

\section{Conclusion}

Polyacrylonitrile nanoparticles have been synthesized via soap-free emulsion polymerization method from acrylonitrile monomer. With the activation of $\mathrm{KOH}$, materials of nanostructure microspheres based on PAN have been produced under different activation temperatures, wherein the specific surface area and mesopores rate can be achieved as high as $2134 \mathrm{~m}^{2} / \mathrm{g}$ and $41.84 \%$, respectively. The specific capacitance of the electrode materials reaches as high as $311 \mathrm{~F} / \mathrm{g}$ and $179 \mathrm{~F} / \mathrm{g}$ in $3 \mathrm{M} \mathrm{KOH}$ electrolyte and $1 \mathrm{M}$ $\left(\mathrm{C}_{2} \mathrm{H}_{5}\right)_{4} \mathrm{NBF}_{4}$ Propylene Carbonate (PC), respectively. The effect of pseudocapacitance of nitrogen-containing functional groups (N-6 and N-5) on electrode materials plays significant role, which causes the materials to obtain excellent wettability.

\section{Conflict of Interests}

The authors declare that there is no conflict of interests regarding the publication of this paper. 


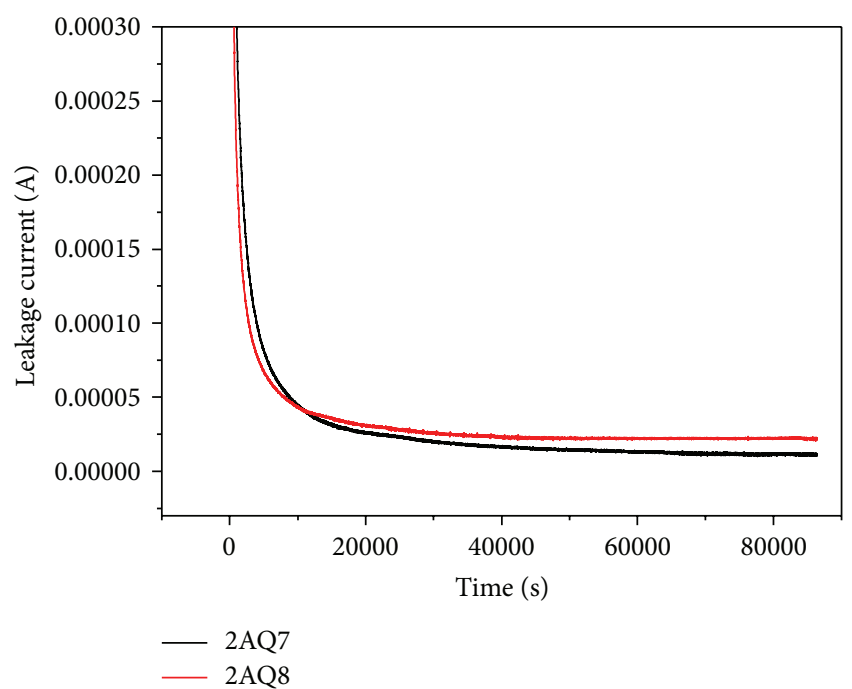

(a)

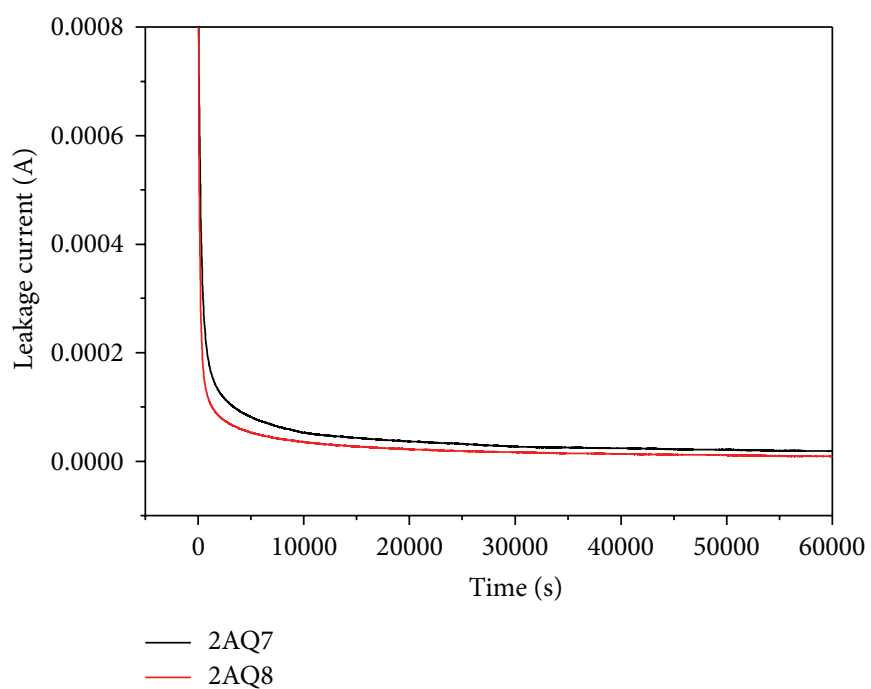

(b)

Figure 11: ((a) and (b)) Leakage current curve in $\mathrm{KOH}$ and $\left(\mathrm{C}_{2} \mathrm{H}_{5}\right)_{4} \mathrm{NBF}_{4} / \mathrm{PC}$ electrolyte of PAN carbon materials.

\section{Acknowledgments}

This work was supported by the National Natural Science Foundation of China (U1361119), Natural Science Research Program of Henan Provincial Education Department (2011B440006), and Doctoral Foundation of Henan Polytechnic University (B2010-82).

\section{References}

[1] P. Simon and Y. Gogotsi, "Materials for electrochemical capacitors," Nature Materials, vol. 7, no. 11, pp. 845-854, 2008.

[2] C. Tran and V. Kalra, "Fabrication of porous carbon nanofibers with adjustable pore sizes as electrodes for supercapacitors," Journal of Power Sources, vol. 235, pp. 289-296, 2013.

[3] R. Pietrzak, K. Jurewicz, P. Nowicki, K. Babeł, and H. Wachowska, "Microporous activated carbons from ammoxidised anthracite and their capacitance behaviours," Fuel, vol. 86, no. 7-8, pp. 1086-1092, 2007.

[4] V. V. Strelko, V. S. Kuts, and P. A. Thrower, "On the mechanism of possible influence of heteroatoms of nitrogen, boron and phosphorus in a carbon matrix on the catalytic activity of carbons in electron transfer reactions," Carbon, vol. 38, no. 10, pp. 1499-1503, 2000.

[5] M. Seredych, D. Hulicova-Jurcakova, G. Q. Lu, and T. J. Bandosz, "Surface functional groups of carbons and the effects of their chemical character, density and accessibility to ions on electrochemical performance," Carbon, vol. 46, no. 11, pp. 14751488, 2008.

[6] Z. Li, C. Tong, C. Mengyu et al., "Research on reaction mechanism and preparation methods of soap-free emulsion polymerization," China Adhesives, vol. 17, no. 4, pp. 47-52, 2008.

[7] J. Jiang, H. Chen, Z. Wang et al., "Nitrogen-doped hierarchical porous carbon microsphere through $\mathrm{KOH}$ activation for supercapacitors," Journal of Colloid and Interface Science, vol. 452, pp. 54-61, 2015.
[8] M. Zhou, F. Pu, Z. Wang, and S. Guan, "Nitrogen-doped porous carbons through $\mathrm{KOH}$ activation with superior performance in supercapacitors," Carbon, vol. 68, pp. 185-194, 2014.

[9] H. Zhao, K. S. Hui, and K. N. Hui, "Synthesis of nitrogendoped multilayer graphene from milk powder with melamine and their application to fuel cells," Carbon, vol. 76, pp. 1-9, 2014.

[10] S. Yao, Z. Shi, and D. Xie, "The structure property and application of conductive material of pyrolytic polyacrylonitrile," Journal of Northeast Normal University, vol. 33, no. 1, pp. 39-40, 2001.

[11] H. Ghorbani, H. Tavanai, and M. Morshed, "Fabrication of activated carbon nanoparticles from PAN precursor," Journal of Analytical and Applied Pyrolysis, vol. 110, no. 1, pp. 12-17, 2014.

[12] X. Jianwen, F. Jing, and S. Li, "PAN fiber carbonized reaction mechanism," Hi-Tech Fiber \& Application, vol. 30, no. 1, pp. 2426, 2005.

[13] Y. V. Tamarkina, V. A. Kucherenko, and T. G. Shendrik, "Alkaline activation of coals and carbon-base materials," Solid Fuel Chemistry, vol. 48, no. 4, pp. 251-259, 2014.

[14] R.-Q. Sun, L.-B. Sun, Y. Chun, and Q.-H. Xu, "Catalytic performance of porous carbons obtained by chemical activation," Carbon, vol. 46, no. 13, pp. 1757-1764, 2008.

[15] B. Xing, C. Zhang, and L. Chen, "Preparation and electrochemical performance of coal-based activated carbons for electric double layer capacitor," Materials Review, vol. 23, no. 22, pp. 106-109, 2009.

[16] Y. Liu, Z. Hu, K. Xu, X. Zheng, and Q. Gao, "Surface modification and performance of activated carbon electrode material," Acta Physico-Chimica Sinica, vol. 24, no. 7, pp. 1143-1148, 2008.

[17] G. Lota, K. Lota, and E. Frackowiak, "Nanotubes based composites rich in nitrogen for supercapacitor application," Electrochemistry Communications, vol. 9, no. 7, pp. 1828-1832, 2007.

[18] E. Frackowiak, "Carbon materials for supercapacitor application," Physical Chemistry Chemical Physics, vol. 9, no. 15, pp. 1774-1785, 2007. 
[19] W. G. Pell, B. E. Conway, and N. Marincic, "Analysis of nonuniform charge/discharge and rate effects in porous carbon capacitors containing sub-optimal electrolyte concentrations," Journal of Electroanalytical Chemistry, vol. 491, no. 1-2, pp. 9-21, 2000.

[20] Y.-R. Nian and H. Teng, "Influence of surface oxides on the impedance behavior of carbon-based electrochemical capacitors," Journal of Electroanalytical Chemistry, vol. 540, pp. 119127, 2003. 

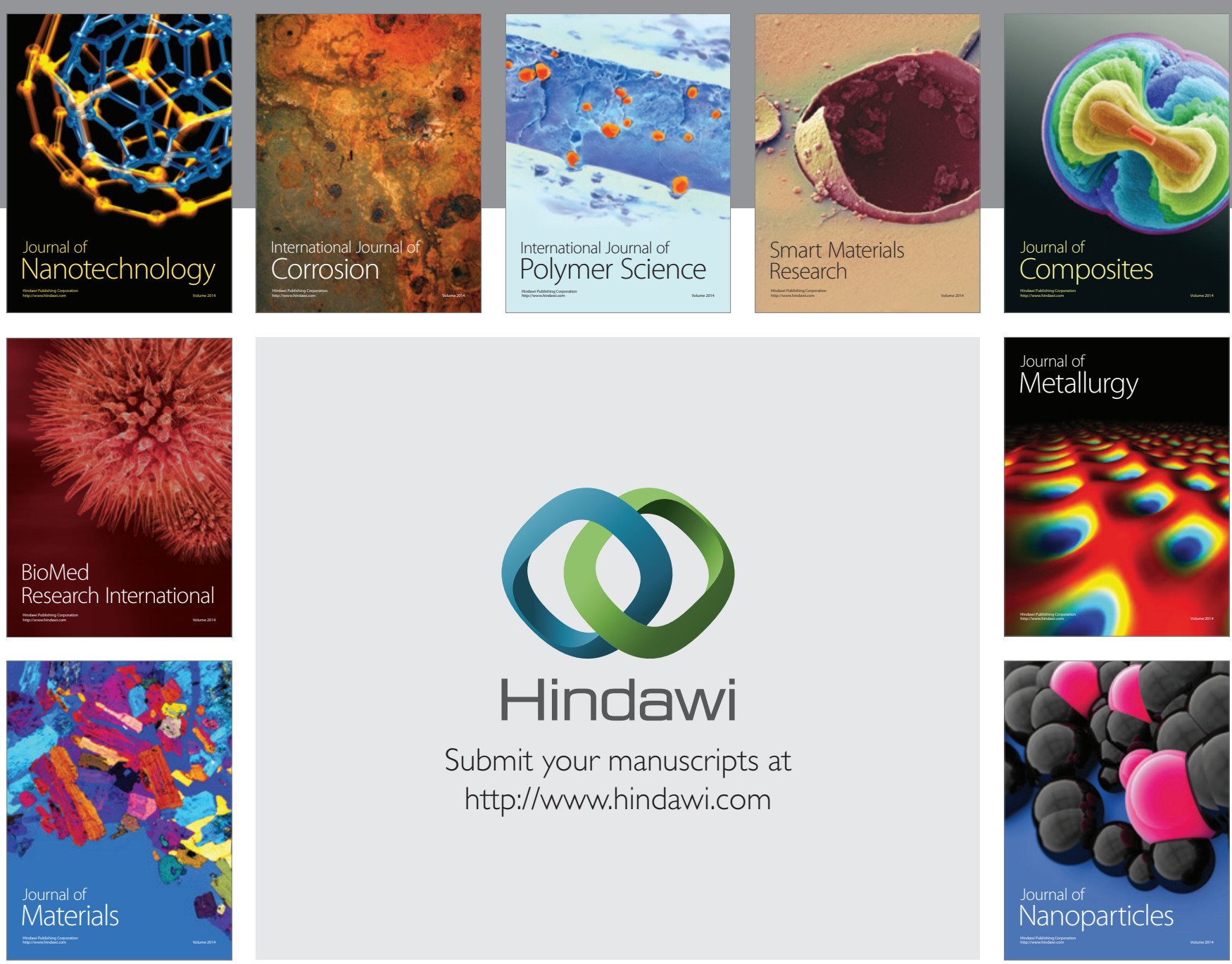

Submit your manuscripts at http://www.hindawi.com
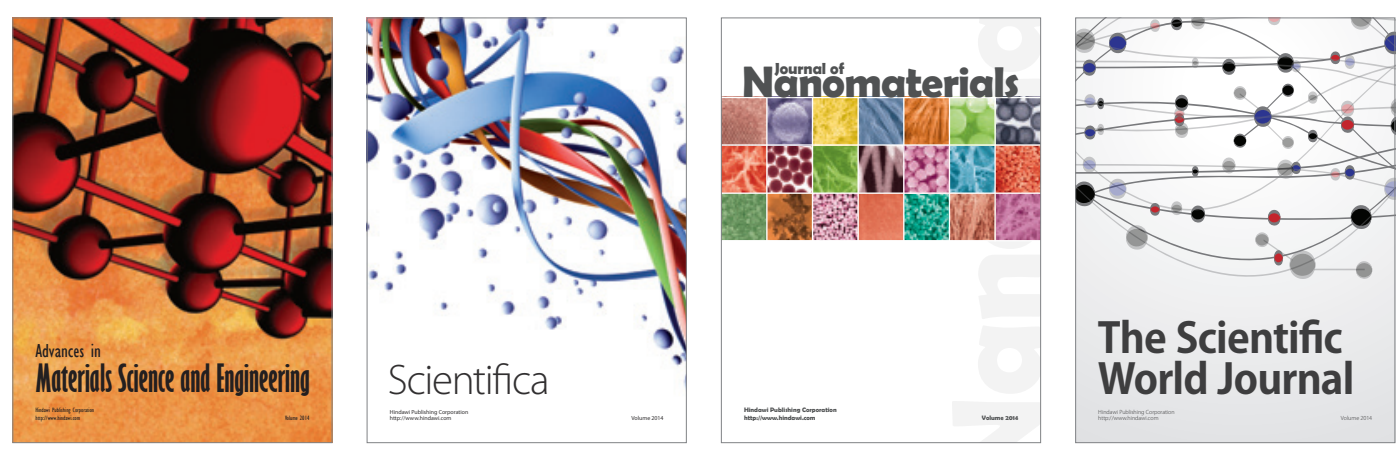

\section{The Scientific World Journal}
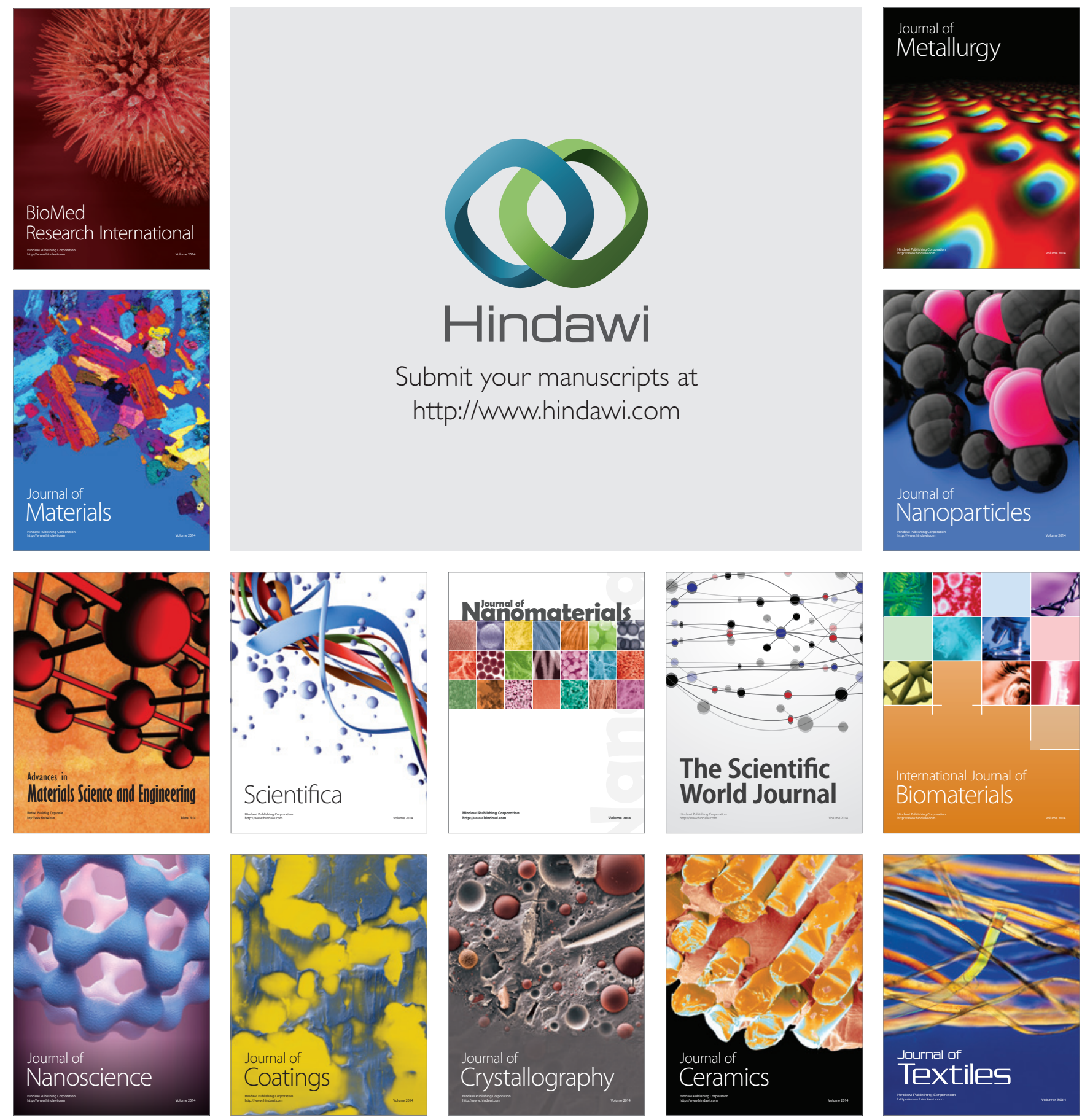